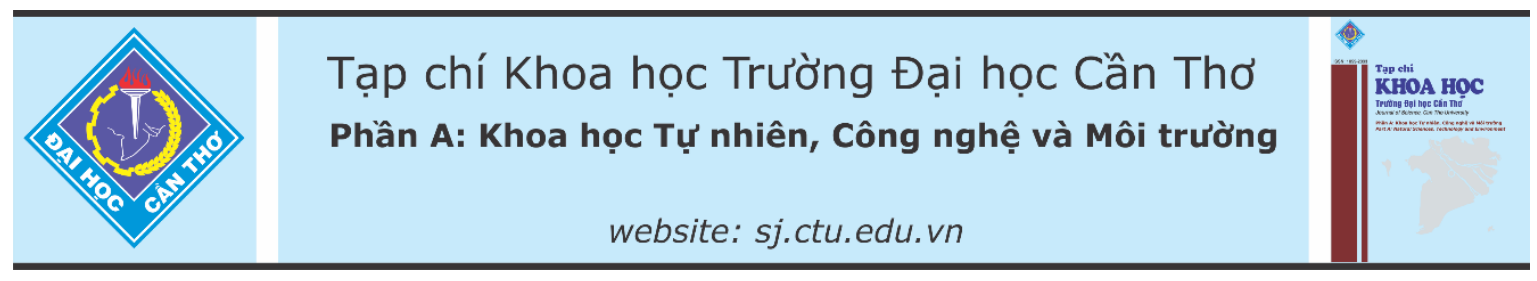

DOI:10.22144/ctu.jvn.2021.038

\title{
TỔNG HỢP, TIẾP CẬN DƯợC LÝ VÀ ĐÁNH GIÁ KHẢ NĂNG ỨC CHẾ ENZYME HISTONE DEACETYLASE 8 (HDAC8) in silico CỦA MỘT SỐ DẪN XUÂTT TƯơnG TỬ BELINOSTAT
}

Nguyễn Cường Quốc ${ }^{1}$, Nguyễn Thị Huỳnh Trang ${ }^{2}$, Huỳnh Thanh Ngân ${ }^{2}$, Đặng Thị Thu Thảo ${ }^{3}$, Nguyễn Trọng Tuân ${ }^{4}$, Bùi Thị Bửu Huế và Trần Quang Đệ 4* $^{*}$

${ }^{1}$ Lớp Hóa Học K43, Khoa Khoa học Tụ nhiên, Truờng Đại học Cần Tho

${ }^{2}$ Lớp Hóa Dược 1-K44, Khoa Khoa họ Tư nhiên, Truờng Đại học Cần Tho

${ }^{3}$ Lóp Hóa Dược 2-K44, Khoa Khoa học Tự nhiên, Truờng Đại học Cần Tho

${ }^{4}$ Khoa Khoa học Tự nhiên, Truờng Đại học Cần Tho

*Nguời chịu trách nhiệm về bài viết: Trần Quang Đệ (email: tqde@ @ctu.edu.vn)

\section{Thông tin chung:}

Ngày nhận bài: 02/11/2020

Ngày nhận bài sủa: 08/12/2020

Ngày duyệt đăng: 28/04/2021

Title:

Synthesis, approaches pharmacological activity and evaluation of belinostat analogues targeting histone deacetylase 8 (HDAC8)

enzymes in silico

\section{Tù khóa:}

Belinostat, histone deacetylase, in silico, ung thu, phản úng Wittig

Keywords:

Belinostat, cancer, histone deacetylase, in silico, Wittig reaction

\section{ABSTRACT}

Cancer treatment drugs are currently in the interest of researchers and the enzyme histone deacetylase (HDAC) is considered a most important molecular target. In 2014, belinostat (Beleodaq) was approved by the FDA as a potent inhibitor of HDAC. Belinostat has been proved to be a cure/treatment for solid tumours and haematological malignancies in clinical trials. Based on the strong activity of belinostat, two belinostat analogues were successfully synthesizedthrough a Wittig reaction with the aim of creating new derivatives that have the potential to selectively inhibit HDAC to contribute to cancer treatment. By keeping the carbon bridge part and the hydroxamic function group intact, the phenyl frame of belinostat is replaced with amine derivatives bearing different $R$ substituents. The derivatives were considered for HDAC8 inhibition based on the in silico method.

\section{TÓM TẮT}

Thuốc điều trị ung thu hiện nay đang được sự quan tâm của các nhà nghiên cúu khoa hoc và enzyme histone deacetylase (HDAC) đượ đánh giá là một đích phần tủ quan trọng nhất. Năm 2014, belinostat (Beleodaq) đuợc FDA phê duyệt là một chất ức chế mạnh HDAC. Belinostat đã đuợc chứng minh là một phương pháp điều trị các khối u rắn và khối u ác tính huyết học trong các thư nghiệm lâm sàng. Dựa trên hoạt tính mạnh của belinostat, hai dẫn xuất tương tụ Belinostat đã được tổng hợp thành công thông qua phản ứng Wittig với muc đích tạo ra các dẫn xuất mới có tiềm năng ức chế chon loc HDAC góp phần điều trị ung thu. Bằng cách giư nguyên phần cầu nối carbon và nhóm chức hydroxamic, thay khung phenyl của belinostat bằng các dẫn xuất amine mang các nhóm thế $R$ khác nhau. Các dẫn xuất được khảo sát khả năng ức chế HDAC8 dụa trên phuong pháp in silico. 


\section{GIỚI THIÊU}

Enzyme histone deacetylase (HDAC) đóng vai trò quan trọng trong việc cân bằng nội môi của quá trình acetyl hóa protein trong histone và các protein khác (Chuang et al., 2009). HDAC đã được chứng minh là rất quan trọng trong sự tiến triển của ung thư. Trong tế bào ung thư có sự huy động quá mức các enzyme HDAC làm giảm sự acetyl hoá của histone ảnh hưởng đến quy định biểu hiện gen. Những thay đổi sự biểu hiện và đột biến của gen mã hóa HDAC có liên quan đến sự phát triển của khối u vì gây ra sự phiên mã sai lệch của các gen quan trọng quy định các chức năng của tế bào như tăng sinh tế bào, điều hòa chu kỳ tế bào và quá trình chết của tế bào (Ropero \& Esteller, 2007). Do đó, chất ức chế HDAC đang là đích phát triển của các nhà nghiên cứu. Tổng cộng có 18 loại enzyme HDAC phân bố khắp trong cơ thể con người và được phân thành bốn nhóm. Trong đó, HDAC 8 được đánh giá là biểu hiện cao và liên quan đến việc xâm lấn tiến triển tế bào ung thư vú (Park et al., 2011). HDAC8 còn liên quan đến u nguyên bào thần kinh, u lympho tế bào $T$ và bệnh bạch cầu dòng tủy cấp tính (Oehme et al., 2009). Nghiên cứu gần đây cho thấy ức chế HDAC 8 cũng có thể là một phương pháp tiềm năng để điều trị rối loạn thần kinh và bệnh ký sinh trùng (Rodrigues et al., 2016). Ngoài ra, đặc điểm cấu trúc của HDAC8 còn cho phép thiết kế các chất ức chế một cách chọn lọc (Chakrabarti et al., 2015). Trong nghiên cứu này, hai dẫn chất tương tự belinostat đã được thiết kế và tổng hợp theo hướng ức chế chọn lọc ưu tiên chống lại các bệnh liên quan đến HDAC8 (Hình 1).

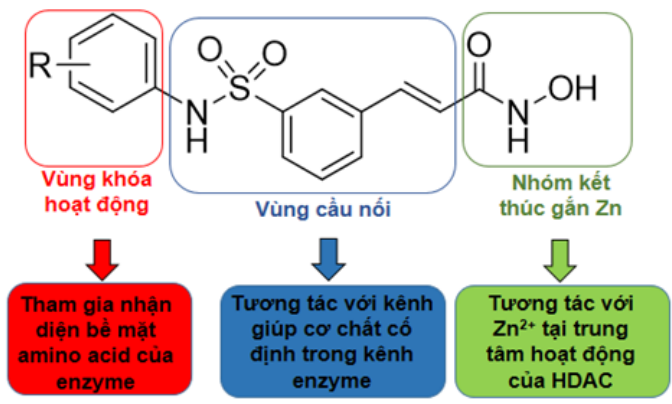

Hình 1. Cấu trúc chung của các dẫn xuất tương tự belinostat ức chế HDAC

Các chất ức chế HDAC (HDACi) là một nhóm phân tử đa dạng về cấu trúc có thể gây ra sự ngừng phát triển, biệt hóa và chết của tế bào ung thư (Dokmanovic \& Marks, 2005). Năm 2014, belinostat đã được FDA (Food and Drug Administration) phê duyệt là chất ức chế ung thư đầy tiềm năng có cấu trúc thuộc loại hydroxamic acid. Belinostat đã được thử nghiệm trong các thử nghiệm lâm sàng giai đoạn I và II chống lại các khối u rắn, chẳng hạn như u trong biểu mô màng phổi ác tính (Ramalingam et al., 2009), khối u biểu mô tuyến ức (Giaccone et al., 2011), tế bào gan không thể cắt bỏ (Yeo et al., 2012), buồng trứng, ống dẫn trứng hoặc ung thư biểu mô phúc mạc nguyên phát (Dizon \& Blessing et al., 2012; Dizonand Damstrup et al., 2012), điều trị bệnh nhân bị bệnh ngoại vi tái phát hoặc khó chữa U lympho tế bào T (PTCL) (Sawas et al., 2015). Kế thừa hoạt tính sinh học cao của belinostat, nghiên cứu đã tổng hợp thành công các dẫn xuất tương tự belinostat với mục đích tạo ra các dẫn chất mới có hoạt tính ức chế tế bào ung thư một cách chọn lọc trên enzyme HDAC8. Bằng cách giữ nguyên phần cầu nối carbon và nhóm chức hydroxamic, thay khung phenyl của belinostat bằng các dẫn xuất amine mang các nhóm thế $\mathrm{R}$ khác nhau. Các dẫn xuất được khảo sát và đánh giá hoạt tính ức chế HDAC8 dựa vào sự trợ giúp của các phần mềm trên máy tính hay còn gọi là phương pháp in silico.

\section{NGUYÊN LIÊUU VÀ PHƯƠNG PHÁP NGHIÊN CÚU}

\subsection{Nguyên liệu}

Phổ ${ }^{1} \mathrm{H}-\mathrm{NMR}$ được đo trên máy cộng hưởng từ hạt nhân Bruker Avance 500 NMR Spetrometer (độ dịch chuyển hóa học $\delta$ được tính theo ppm, hằng số tương tác $J$ tính bằng $\mathrm{Hz}$ ) tại Viện Hóa học - Viện Hàn Lâm Khoa học Việt Nam và máy cộng hưởng từ hạt nhân Bruker 300 NMR tại Đài Loan. Phổ khối lượng MS được đo trên máy 1100 series LC/MS/MS Trap Agilent. Các hóa chất và dung môi sử dụng có nguồn gốc từ Merck, Ân Độ, Trung Quốc và Việt Nam. Sắc ký bản mỏng sử dụng bản nhôm silica gel $60 \mathrm{~F}_{254}$ tráng sẵn độ dày $0,2 \mathrm{~mm}$ (Merck). Sắc ký cột sử dụng silica gel cỡ hạt 0,04-0,06 mm (Merck). Các phần mềm sử dụng Chem3D 16.0, Gaussian $09 \mathrm{~W}$, GaussView 6.0, Open Babel, AutoDock 4.2, AutoDock Vina, Discovery Studio 2019 Client. Cấu trúc tinh thể HDAC8 (1T67) ở người được tải xuống từ cơ sở dữ liệu protein data bank (https://www.rcsb.org/structure/1T67). Protein data bank (PDB) là ngân hàng quốc tế chứa hơn 81000 dữ liệu cấu trúc protein ba chiều, phần lớn chúng được xác định bằng phương pháp tinh thể tia $\mathrm{X}$, còn lại được xác định bằng phổ cộng hưởng từ NMR.

\subsection{Phương pháp nghiên cứu}

\subsubsection{Quy trình tổng hợp}

\section{Tổng hợp 3-nitrobenzaldehyde (2)}

Cân $\mathrm{KNO}_{3}(3 \mathrm{~g}, 30 \mathrm{mmol})$ cho vào bình cầu 100 $\mathrm{mL}$, thêm tiếp $12 \mathrm{~mL}$ dung dịch $\mathrm{H}_{2} \mathrm{SO}_{4}$ đậm đặc, hỗn 
hợp được khuấy trong bể nước đá khoảng 5 phút sau đó cho từ từ benzaldehyde $(3,18 \mathrm{~g}, 30 \mathrm{mmol})$ vào, sau khoảng 2 giờ rót hỗn hợp vào cốc nước đá, thấy xuất hiện kết tửa, lọc lấy tủa, rửa kết tủa lần lượt với nước lạnh và $\mathrm{NaHCO}_{3} 5 \%$. Tinh chế hỗn hợp thô bằng sắc ký cột silica gel với hệ dung môi HexaneEthyl acetate $\left(\right.$ Hex:EtOAc) $=4: 1, \mathrm{R}_{f}=0,42$. Thu được sản phẩm màu vàng nhạt, $3,19 \mathrm{~g}$. Hiệu suất đạt $70 \%$.

Dữ liệu phổ: ${ }^{1} \mathrm{H}-\mathrm{NMR}\left(300 \mathrm{MHz}, \mathrm{CDCl}_{3}, \delta\right.$ ppm): 10,12 (s, 1H, -CHO), 8,71 (dd, $J=1,8 \mathrm{~Hz}$, $1 \mathrm{H},>\mathrm{CH}), 8,47-8,71$ (m, 1H, >CH-), 8,21-8,25 (m, $1 \mathrm{H},>\mathrm{CH}-), 7,76(\mathrm{t}, J=7,95 \mathrm{~Hz}, 1 \mathrm{H},>\mathrm{CH}-)$.

Tổng hợp chất trung gian ylide (methyl (triphenylphosphoranylidene)acetate) (3)

Thêm từ từ triphenylphosphine $(768 \mathrm{mg}, 3$ mmol) vào ethyl chloroacetate $(405 \mathrm{mg}, 3,3 \mathrm{mmol})$ trong bình cầu $100 \mathrm{~mL}$ chứa $12 \mathrm{~mL} \mathrm{H} \mathrm{H}_{2} \mathrm{O}$. Khuấy đều hỗn hợp với tốc độ 700 vòng/phút ở nhiệt độ $70^{\circ} \mathrm{C}$ với thời gian 20 giờ, thu được hỗn hợp màu vàng, làm lạnh, thêm từ từ dung dịch $\mathrm{NaOH}(264 \mathrm{mg}, 6,6$ $\mathrm{mmol}$ ) trong $\mathrm{H}_{2} \mathrm{O}$. Khuấy đều hỗn hợp ở nhiệt độ phòng trong 5 phút. Chiết sản phẩm với methylen chloride (MC), dịch chiết rửa lại với dung dịch $\mathrm{NaCl}$ bão hoà, làm khan bằng $\mathrm{Na}_{2} \mathrm{SO}_{4}$, cô đuồi dung môi thu được chất rắn màu vàng. Sản phẩm được sử dụng trực tiếp cho giai đoạn tiếp theo mà không cần tinh chế.

\section{(W04) \\ Tổng hợp (E)-3-(3-nitrophenyl)acrylate}

Cân hỗn hợp methyl(triphenylphosphoranylidene)acetate $\quad(350$ $\mathrm{mg}, 1 \mathrm{mmol})$ và $2(300 \mathrm{mg}, 1 \mathrm{mmol})$ trong bình cầu $25 \mathrm{~mL}$ chứa $5 \mathrm{~mL} \mathrm{H}_{2} \mathrm{O}$. Khuấy đều hỗn hợp với tốc độ 700 vòng/phút ở nhiệt độ $90^{\circ} \mathrm{C}$ trong thời gian 1 giờ. Hỗn hợp sau phản ứng được chiết với EtOAc nhiều lần và làm khan bằng $\mathrm{Na}_{2} \mathrm{SO}_{4}$, cô đuổi dung môi thu được sản phẩm thô, tiến hành kết tinh sản phẩm thu được chất rắn màu vàng. Tinh chế sản phẩm bằng sắc ký cột silica gel (Hex:EtOAc $=5: 1$, $\left.\mathrm{R}_{f}=0,35\right)$. Thu được chất rắn màu trắng, $243 \mathrm{mg}$. Hiệu suất: $64,3 \%$.

Dũ liệu phổ: ${ }^{1} \mathrm{H}-\mathrm{NMR}\left(300 \mathrm{MHz}, \mathrm{CDCl}_{3}, \delta\right.$ ppm): 8,37 (d, $J=1,8 \mathrm{~Hz}, 1 \mathrm{H},>\mathrm{CH}-), 8,24$ (dd, $J_{l}=$ $\left.1,5 \mathrm{~Hz}, J_{2}=1,2 \mathrm{~Hz}, 1 \mathrm{H},>\mathrm{CH}-\right), 7,80(\mathrm{~d}, J=7,8 \mathrm{~Hz}$, $1 \mathrm{H},>\mathrm{CH}-), 7,72(\mathrm{~d}, J=15,9 \mathrm{~Hz}, 1 \mathrm{H},=\mathrm{CH}-), 7,58$ $(\mathrm{t}, J=7,95 \mathrm{~Hz}, 1 \mathrm{H},>\mathrm{CH}-), 6,55(\mathrm{~d}, J=15,9 \mathrm{~Hz}, 1 \mathrm{H}$, $=\mathrm{CH}-), 3,83\left(\mathrm{~s}, 3 \mathrm{H},-\mathrm{CH}_{3}\right)$.

Tổng hợp
aminophenyl)acrylate (5) methyl $\quad(E)-3-(3-$

Hoà tan W04 $(2,07 \mathrm{~g}, 10 \mathrm{mmol})$ và $\mathrm{SnCl}_{2} .2 \mathrm{H}_{2} \mathrm{O}$ $(7,9 \mathrm{~g}, 35 \mathrm{mmol})$ vào $300 \mathrm{~mL}$ EtOH khan trong bình cầu $500 \mathrm{~mL}$. Đun hồi lưu hỗn hợp ở nhiệt độ $90^{\circ} \mathrm{C}$. Sau 3 giờ, theo dõi phản ứng bằng TLC đến khi không còn xuất hiện W04, ngưng phản ứng, để nguội, trung hoà bằng $\mathrm{Na}_{2} \mathrm{CO}_{3}$ bão hoà, hỗn hợp được chiết với EtOAc, cô đuổi dung môi và tinh chế sản phẩm bằng sắc ký cột silica gel với hệ dung môi Hex:EtOAc $=5: 1, \mathrm{R}_{f}=0,26$. Thu được sản phẩm màu trắng vàng, $1,58 \mathrm{~g}$. Hiệu suất $89 \%$.

Dữ liệu phổ: ${ }^{1} \mathrm{H}-\mathrm{NMR}\left(300 \mathrm{MHz}, \mathrm{CDCl}_{3}, \delta\right.$ ppm): 7,60 (d, $J=15,9 \mathrm{~Hz}, 1 \mathrm{H},=\mathrm{CH}-), 7,17$ (t, $J=$ $7,65 \mathrm{~Hz}, 1 \mathrm{H},>\mathrm{CH}-), 6,92(\mathrm{~d}, J=7,8 \mathrm{~Hz}, 1 \mathrm{H},>\mathrm{CH}-$ ) $6,81(\mathrm{t}, J=1,8 \mathrm{~Hz}, 1 \mathrm{H},>\mathrm{CH}-), 6,68-6,72(\mathrm{~m}, 1 \mathrm{H}$, $>\mathrm{CH}-$ ) , 6,37 (d, J= 15,9 Hz, 1H, =CH-), 3,79 (s, $\left.1 \mathrm{H},-\mathrm{CH}_{3}\right), 3,73\left(\mathrm{~s}, 2 \mathrm{H},-\mathrm{NH}_{2}\right)$.

Tổng hợp chất trung gian methyl $(E)-3-(3-$ (chlorosulfonyl)phenyl)acrylate (5')

Hòa $\tan 1$ g methyl (E)-3-(3aminophenyl)acrylate (5) trong hỗn hợp $6 \mathrm{~mL} \mathrm{HCl}$ đậm đặc và $2 \mathrm{~mL}$ acetic acid đậm đặc, làm lạnh hỗn hợp. Sau 5 phút thêm từ từ $3 \mathrm{~mL}$ dung dịch $\mathrm{NaNO}_{2}$ $4 \mathrm{M}$ giữ phản ứng ở nhiệt độ nhỏ hơn $5^{\circ} \mathrm{C}$, khuấy hỗn hợp trong 45 phút. Trong một bình cầu khác khí $\mathrm{SO}_{2}$ được sục vào $10 \mathrm{~mL}$ acetic acid ở nhiệt độ nhỏ hơn $5^{\circ} \mathrm{C}$ đến khi bão hòa. Thêm tiếp $50 \mathrm{mg} \mathrm{CuCl}$ vào, tiếp tục sục khí $\mathrm{SO}_{2}$ cho đến khi dung dịch từ màu xanh lục chuyển sang màu xanh nhạt. Thêm từ từ dung dịch muối diazonium ban đầu vào hỗn hợp trên và tiếp tục khuấy ở nhiệt độ nhỏ hơn $5^{\circ} \mathrm{C}$. Sau 2 giờ, chiết hỗn hợp phản ứng với EtOAc thu lấy lớp hữu cơ, làm khan bằng $\mathrm{Na}_{2} \mathrm{SO}_{4}$. Tiến hành cô đuổi dung môi, thu được sản phẩm ở dạng tủa màu vàng nâu, sản phẩm được sử dụng trực tiếp cho bước tiếp theo mà không cần tinh chế. Lưu ý, nên giữ nhiệt độ của bể cô quay không vượt quá $40^{\circ} \mathrm{C}$ do sản phẩm rất dễ bị phân hủy ở nhiệt độ cao.

\section{Tổng hợp các sulfonamide mang nhóm chức hydroxamic acid}

Hòa tan amine (h hoặc v) 0,45 mmol trong $3 \mathrm{~mL}$ 1,4-dioxane và $5 \mathrm{~mL}$ dung dịch $\mathrm{NaHCO}_{3} 10 \%$ sau đó nhỏ từ từ hỗn hợp dung dịch chất trung gian $\left(5^{\prime}\right)$ trong $4 \mathrm{~mL}$ 1,4-dioxane vào, phản ứng được khuấy ở nhiệt độ phòng, theo dõi phản ứng bằng TLC. Sau 12 giờ, tiến hành cô đuổi một phần dung môi, thêm tiếp vào $6 \mathrm{~mL}$ nước khuấy tiếp trong 1 giờ. Tiến hành chiết với EtOAc, rửa dịch chiết nhiều lần với dung dịch $\mathrm{HCl} 1 \mathrm{~N}$. Thu lấy lớp hữu cơ, cô đuổi dung môi, tinh chế sản phẩm bằng sắc ký cột silica gel với hệ dung môi Hex:EtOAc $=5: 1$ thu được chất rắn 
vàng. Kết tinh lại sản phẩm, thu được chất rắn màu trắng.

Sau đó, hòa tan lượng chất rắn trên trong $\mathrm{EtOH}$, cho từ từ hỗn hợp vào bình cầu chứa sẵn $1 \mathrm{~g} \mathrm{KOH}$, $1,5 \mathrm{~g} \mathrm{NH}_{2} \mathrm{OH} . \mathrm{HCl}$ trong $10 \mathrm{~mL}$ EtOH khan, hỗn hợp được khuấy đều, làm lạnh dưới $5^{\circ} \mathrm{C}$, theo dõi phản ứng bằng TLC. Sau 1 giờ, trung hòa hỗn hợp bằng $\mathrm{HCl} 2 \mathrm{~N}$ đến khi quỳ tím hóa hồng. Tiến hành chiết nhiều lần với EtOAc, làm khan bằng $\mathrm{Na}_{2} \mathrm{SO}_{4}$, cô đuổi dung môi và tinh chế sản phẩm bằng sắc ký cột silica gel với hệ dung môi Hex:EtOAc $=1: 1$, thu được chất rắn màu vàng. Kết tinh lại sản phẩm.

(E)- $\mathrm{N}$-Hydroxy-3-(3- $(\mathrm{N}-(4-$

methoxyphenyl)sulfamoyl)phenyl)acrylamide (7h): chất rắn không màu. Hiệu suất cho cả hai bước là $8,76 \% . \mathrm{R}_{f}=0,55$ (EtOAc). Dũ̃ liệu phổ: ${ }^{1} \mathrm{H}-\mathrm{NMR}$ $(500 \mathrm{MHz}, \mathrm{DMSO}, \delta \mathrm{ppm}): 10,81(\mathrm{~s}, 1 \mathrm{H},-\mathrm{OH})$, 9,94 (s, 1H, >NH), 9,10 (s, 1H, >NH), 7,85 (s, 1H, $>\mathrm{CH}-), 7,76(\mathrm{~d}, J=7,5 \mathrm{~Hz}, 1 \mathrm{H},>\mathrm{CH}-), 7,62(\mathrm{~d}, J=$ $7,5 \mathrm{~Hz}, 1 \mathrm{H},>\mathrm{CH}-), 7,56(\mathrm{t}, J=7,5 \mathrm{~Hz}, 1 \mathrm{H},>\mathrm{CH}-)$, $7,46(\mathrm{~d}, J=16 \mathrm{~Hz}, 1 \mathrm{H},=\mathrm{CH}-), 6,97(\mathrm{~d}, J=9 \mathrm{~Hz}$, $2 \mathrm{H}, 2>\mathrm{CH}-), 6,81-6,79$ (m, 2H, $2>\mathrm{CH}-), 6,50$ (d, $J=15,5 \mathrm{~Hz}, 1 \mathrm{H},=\mathrm{CH}-), 3,66\left(\mathrm{~s}, 3 \mathrm{H},-\mathrm{CH}_{3}\right)$. HRMS (ESI) $\mathrm{m} / \mathrm{z},[\mathrm{M}+\mathrm{H}]^{+}$tính toán cho $\mathrm{C}_{16} \mathrm{H}_{17} \mathrm{~N}_{2} \mathrm{O}_{5} \mathrm{~S}$ : 349,0780; tìm thấy: 349,0862.

(E)- $N$-Hydroxy-3-(3-(N-(4- $((Z)-1-$

(hydroxyimino)ethyl)phenyl)sulfamoyl)phenyl)acr ylamide $(\mathbf{7 v})$ : chất rắn màu trắng. Hiệu suất cho cả hai bước là $4,42 \% . \mathrm{R}_{f}=0,45$ (EtOAc). Dữ liệu phổ: ${ }^{1} \mathrm{H}-\mathrm{NMR}$ (500 MHz, DMSO, $\delta \mathrm{ppm}$ ): 11,06 (s, 1H, $-\mathrm{OH}), 10,81(\mathrm{~s}, 1 \mathrm{H},-\mathrm{OH}), 10,46(\mathrm{~s}, 1 \mathrm{H},>\mathrm{NH})$, 9,11 (s, 1H, >NH), 7,95 (s, 1H, >CH-), 7,78 (d, J= $7,5 \mathrm{~Hz}, 1 \mathrm{H},>\mathrm{CH}-), 7,72(\mathrm{~d}, J=7,5 \mathrm{~Hz}, 1 \mathrm{H},>\mathrm{CH}-$ ), $7,58$ (t, $J=7,75 \mathrm{~Hz}, 1 \mathrm{H},>\mathrm{CH}-), 7,52(\mathrm{~d}, J=8 \mathrm{~Hz}$, $2 \mathrm{H}, 2>\mathrm{CH}-), 7,47(\mathrm{~d}, J=15,5 \mathrm{~Hz}, 1 \mathrm{H},=\mathrm{CH}-), 7,11$ (d, $J=8 \mathrm{~Hz}, 2 \mathrm{H}, 2>\mathrm{CH}-), 6,52(\mathrm{~d}, J=16 \mathrm{~Hz}, 1 \mathrm{H}$, $=\mathrm{CH}-), 2,05\left(\mathrm{~s}, 3 \mathrm{H},-\mathrm{CH}_{3}\right)$. HRMS (ESI) $\mathrm{m} / \mathrm{z}$ $[\mathrm{M}+\mathrm{H}]^{+}$tính toán cho $\mathrm{C}_{17} \mathrm{H}_{18} \mathrm{~N}_{3} \mathrm{O}_{5} \mathrm{~S}: 376,0889$; tìm thấy: 376,0974 .

\subsubsection{Docking phân tử}

Trong nghiên cứu này, phương pháp sàng lọc ảo được sử dụng để đánh giá khả năng ức chế và sự tương tác giữa các dẫn chất tổng hợp được với HDAC. Nghiên cứu chọn enzyme HDAC8 là đích phân tử để tiến hành quá trình docking. Cấu trúc của enzyme HDAC8 (ID: 1T67) được lấy từ Ngân hàng dữ liệu protein (Protein data bank www.pdb.org/pdb). Cấu trúc hóa học ban đầu của các dẫn xuất được vẽ trên phần mềm Chemdraw 16.0 và chuyển đổi tự động sang cấu trúc $3 \mathrm{D}$ bằng phần mềm Chem3D 16.0, tối ưu năng lượng thấp chất, tiếp theo quá trình tối ưu hóa cấu trúc phân tử được thực hiện bằng phần mềm Gausian $09 \mathrm{~W}$ với phương pháp bán thực nghiệm (semi-empirical) với bộ hàm cơ bản PM6. Tiến hành docking phân tử giữa ligand và enzyme HDAC8 bằng chương trình AutoDockTools phiên bản v1.5.6 tích hợp Autodock Vina (docking mù) và Autodock4 (redocking). Phần mềm Discovery Studio 2019 Client được sử dụng để phân tích kết quả các tương tác $2 \mathrm{D}$, $3 \mathrm{D}$ giữa cấu trúc HDAC8 phức hợp với các dẫn xuất tổng hợp và so sánh với kết quả của belinostat.

\subsection{3. Đánh giá độc tính in silico}

Các tính toán dự đoán được thực hiện trên các phần mềm Molinspiration, SwissADMET, PreADMET, Osiris Property Explorer và Toxtree 3.1.0. Các phần mềm được khởi động chạy trực tiếp trên Window 10 thông qua trình giả lập nền tảng Java. Các cấu trúc của các dẫn xuất được vẽ trực tiếp trên phần mềm hoặc được nạp trực tiếp vào phần mềm dưới định dạng SMILES, pdb hoặc mol2. Kết quả đầu ra của phần mềm được hiển thị bằng các dãy màu hoặc số liệu. Trong đó có ba màu cơ bản: đỏ (độc tính cao nguy hiểm), vàng (độc tính trung bình có thể sử dụng), lam (độc tính rất thấp hoặc không có độc tính an toàn khi sử dụng). Kết quả hiển thị bằng dạng số liệu được chọn lọc nằm trong khung quy định của cơ sở dữ liệu chuẩn đã được công bố, chất nằm ngoài quy định được loại bỏ và kết quả tiếp theo được so sánh với kết quả của belinostat.

\section{KÊT QUẢ VÀ THẢO LUẬN}

\subsection{Thực nghiệm}

Với quy trình tổng hợp tương đối đơn giản, nguyên liệu rẻ tiền, nước đã được sử dụng nhiều hơn nên thân thiện với môi trường và phù hợp với mô hình thí nghiệm ở Việt Nam. Hai dẫn xuất $\mathbf{7 h}$ và $\mathbf{7 v}$ có khung tương tự belinostat đã được tổng hợp thành công với hiệu suất toàn phần lần lượt là $3,51 \%$ và $2,63 \%$ (Hình 2). Cấu trúc của các hợp chất thu được đã được xác định chính xác và rõ ràng bằng phổ cộng hưởng từ hạt nhân ${ }^{1} \mathrm{H}-\mathrm{NMR}$ và phổ khối lượng MS độ phân giải cao. 


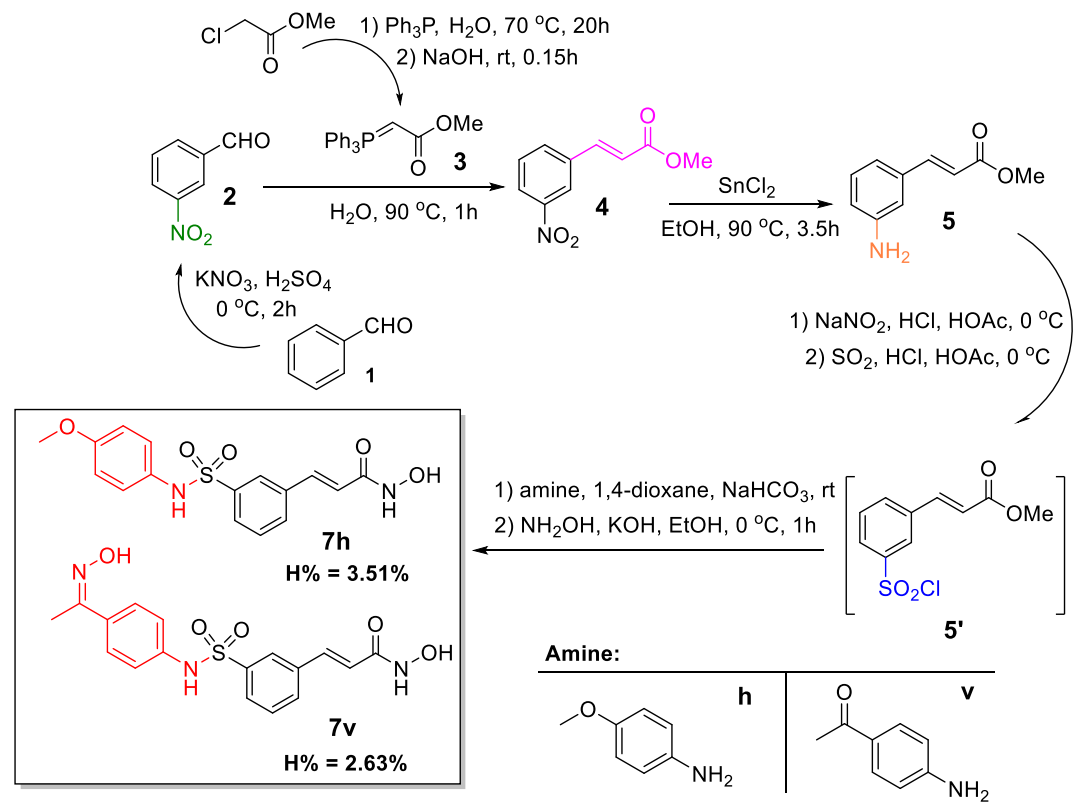

Hình 2. Quy trình tổng hợp các dẫn xuất tương tự belinostat

Cụ thể, dẫn xuất $7 \mathbf{h}$ cho thấy sự xuất hiện của 16 tín hiệu proton. Ở vùng từ trường thấp, có sự xuất hiện của ba tín hiệu singlet với cường độ tích phân tương đối từng tín hiệu bằng 1 và có độ dịch chuyển hóa học lần lượt là $\delta=10,81 \mathrm{ppm}, \delta=9,94 \mathrm{ppm}$ và $\delta=9,10$ ppm đặc trưng cho tín hiệu proton nhóm $-\mathrm{OH}$, proton $>\mathrm{NH}$ của nhóm chức hydroxamate và nhóm $>\mathrm{NH}$ thuộc vùng cầu nối. Các mũi $\delta=7,46$ $\operatorname{ppm}(J=16)$ và $\delta=6,50 \mathrm{ppm}(J=15,5 \mathrm{~Hz})$ đặc trưng cho alkene dạng trans. Ngoài ra, tín hiệu singlet có cường độ mạnh với giá trị tích phân bằng 3 dịch chuyển vùng từ trường thấp $\delta=3,66$ ppm đặc trưng cho nhóm methoxy. Các tín hiệu còn lại nằm trên hai vòng benzene thuộc vùng cầu nối và vùng khóa hoạt động. Phổ HRMS tìm thấy peak ion giả phân tử $m / z[\mathrm{M}+\mathrm{H}]^{+}=349,0862$ phù hợp với công thức $\mathrm{C}_{16} \mathrm{H}_{16} \mathrm{~N}_{2} \mathrm{O}_{5} \mathrm{~S}$. Amine $\mathbf{v}$ là một ketone khi kết hợp với $\mathbf{5}^{\prime}$ dể tạo thành dẫn xuất $\mathbf{7 v}$ do thực hiện trong môi trường kiềm và có sự hiện diện của hydroxylamine nên nhóm ketone bị biến đổi thành dạng ketoxime (Hình 3). Vì vậy, thay vì có sự xuất hiện của 16 tín hiệu proton như dữ liệu phổ $7 \mathbf{h}$ thì 7v lại suất hiện thêm peak tín hiệu singlet với cường độ mạnh ở vùng từ trường thấp $\delta=11,06$ ppm đặc trưng cho tín hiệu proton nhóm -OH của ketoxime. Vì vậy, độ dịch chuyển hóa học ở vị trí $\delta=10,46$ ppm, peak tín hiệu singlet được quy cho proton nhóm $>\mathrm{NH}$ thuộc vùng cầu nối do chịu ảnh hưởng đẩy electron của nhóm ketoxime.

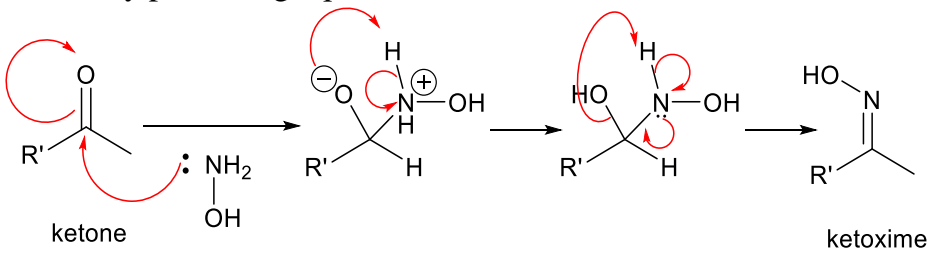

Hình 3. Cơ chế hình thành dạng ketoxime của $7 \mathrm{v}$

Hai tín hiệu singlet với cường độ tích phân tương đối bằng 1 và có độ dịch chuyển hóa học lần lượt là $\delta=10,81$ ppm và $\delta=9,11$ ppm đặc trưng cho tín hiệu proton nhóm $-\mathrm{OH}$, proton $>\mathrm{NH}$ của nhóm chức hydroxamate. Các peak $\delta=7,47 \mathrm{ppm}(J=15,5)$ và $\delta=6,52 \mathrm{ppm}(J=16 \mathrm{~Hz})$ đặc trưng cho alkene dạng trans. Tín hiệu singlet có cường độ mạnh với giá trị tích phân bằng 3 dịch chuyển vùng từ trường thâp $\delta=2,05$ ppm đặc trưng cho ba proton của $-\mathrm{CH}_{3}$ Tám tín hiệu còn lại là của hai vòng benzene trên vùng cầu nối và vùng khóa hoạt động của dẫn xuất 7v. Dữ liệu phổ HRMS của $7 \mathbf{v}$ tìm thấy peak ion giả phân tử $m / z,[\mathrm{M}+\mathrm{H}]^{+}=376,0974$ phù hợp với công thức $\mathrm{C}_{17} \mathrm{H}_{17} \mathrm{~N}_{3} \mathrm{O}_{5} \mathrm{~S}$. Từ các dữ liệu phổ trên đã cho thấy việc tổng hợp hai dẫn xuất $7 \mathbf{h}$ và $7 \mathbf{h}$ tương tự belinostat được thực hiện thành công. 


\section{2. Đánh giá in silico}

Để xem xét và đánh giá khả năng ức chế HDAC của các dẫn chất tổng hợp được. Phương pháp docking phân tử bằng chương trình AutoDock Tools phiên bản v1.5.6 đã được sử dụng để tạo phức hợp giữa các phân tử dẫn xuất với enzyme HDAC8. Việc docking có vai trò quan trọng trong dự đoán ái lực và hoạt tính của các dược chất đối với protein, từ đó dự đoán khả năng hoạt hóa, tâm hoạt động và ức chế đối với enzyme. Sau khi docking sàng lọc để tìm ra vị trí và tư thế hoạt động tối ưu nhất giữa ligand với enzyme HDAC8 bằng phần mềm AutoDock Vina, quá trình docking được thực hiện. Sử dụng lưới giản đồ $40 \times 40 \times 40$ và khoảng cách giữa các điểm là $0,150 \AA ̊$, sử dụng vị trí trung tâm ligand làm chuẩn, các tham số khác được cài đặt mặc định giống tham số của chương trình. Kết quả docking Bảng 2 được hiển thị, sắp xếp và lựa chọn theo tiêu chí năng lượng thấp nhất, kết hợp với giá trị độ lệch căn quân phương RMSD (root-mean square deviation), RMSD có vai trò như là phép đo đạc chất lượng các kết quả docking. Giá trị RMSD thấp trong quá trình mô phỏng, cấu trúc hợp chất và protein không thay đổi hoặc thay đổi rất ít cho thấy tính ổn định của các ligand.

Bảng 2. Giá trị RMSD, năng lượng tự do liên kết dự đoán, giá trị hằng số ức chế $K_{i}$ của kết quả docking các dẩn xuất tương tự belinostat

\begin{tabular}{cccc}
\hline Tên & Giá trị RMSD $(\AA)$ & $\begin{array}{c}\text { Năng lượng tự do liên kết dự đoán } \\
(\mathbf{k c a l} / \mathbf{m o l})\end{array}$ & $\begin{array}{c}\text { Hằng số ú́c chế } \mathbf{K}_{\mathbf{i}} \\
(\mathbf{n M})\end{array}$ \\
\hline $7 \mathrm{~h}$ & 1,956 & $-8,62$ & 481,81 \\
$7 \mathrm{v}$ & 1,504 & $-10,10$ & 39,49 \\
\hline
\end{tabular}

Trung tâm hoạt động HDAC gồm 2 phần chính: ion $\mathrm{Zn}^{2+}$ là coenzyme của HDAC và kênh enzyme dạng túi hình ống, cấu trúc linh động có thể biến đổi phù hợp với chiều dài ligand khác nhau, trên miệng túi có một vành nhỏ được tạo nên từ một vài vòng xoắn protein, phần vành này sẽ tương tác với nhóm nhận diện bề mặt HDAC (Verdin, 2006). Kết quả docking cho thấy các dẫn chất có khả năng liên kết tốt đến trung tâm hoạt động của enzyme HDAC8, giá trị năng lượng tự do liên kết giữa dẫn xuất $7 \mathbf{7 h}$ và $7 \mathbf{v}$ với enzyme thấp lần lượt là $-8,62 \mathrm{kcal} / \mathrm{mol}$ và -
$10,10 \mathrm{kcal} / \mathrm{mol}$. Dẫn xuất $\mathbf{7 h}$ và $\mathbf{7 v}$ tham gia liên kết với hai amino acid His142 và Asp178 ở sâu trong túi liên kết, vùng khóa hoạt động trên cấu trúc của hai dẫn xuất tham gia liên kết với Lys33, Tyr100 và Phe152 trên miệng của túi. Cụ thể, nhóm ketoxime thuộc vùng khóa hoạt động trên dẫn xuất $\mathbf{7 v}$ cho thấy khả năng tham gia liên kết với các amino acid chặt chẽ hơn nhóm methoxy của $\mathbf{7 h}$ ở miệng túi. Nhóm hydroxamic acid hình thành liên kết với $\mathrm{Zn}^{2+}$ và liên kết với nhiều amino acid bằng các tương tác van der Waals, alkyl, pi-alkyl,...(Hình 3 và Hình 4).
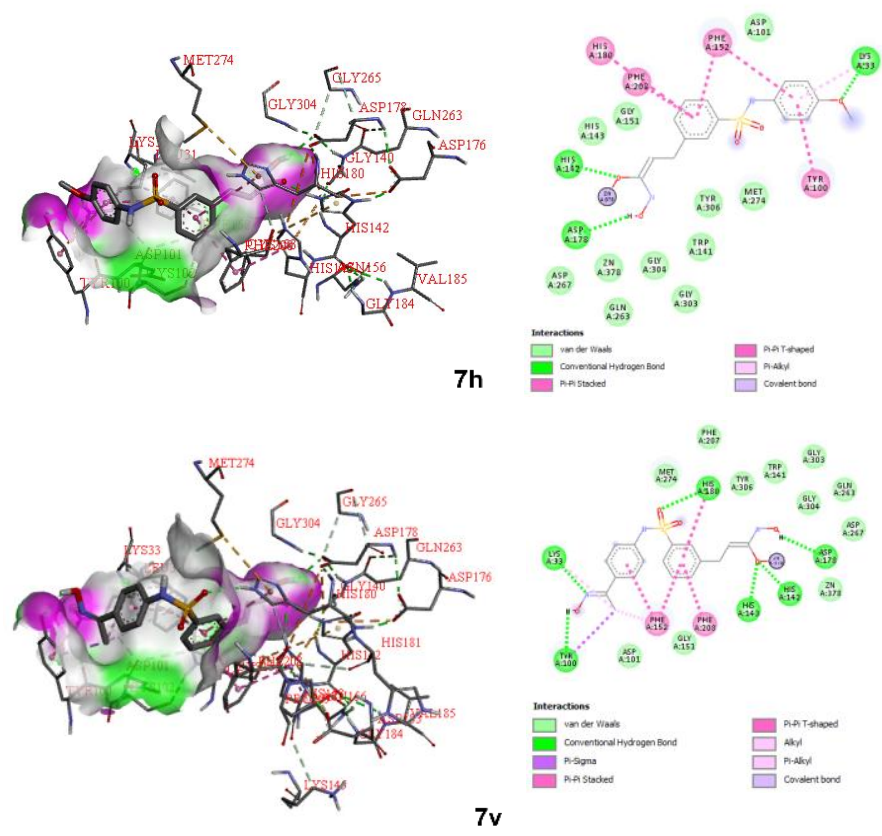

Hình 3. Kết quả docking các dẫn xuất tương tự belinostat trên HDAC8 

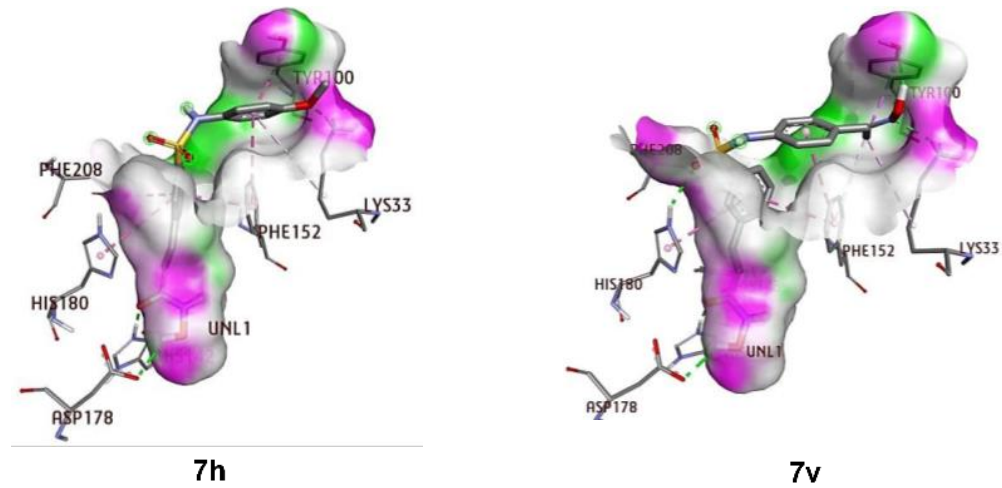

\section{Hình 4. Trung tâm hoạt động dạng tưi hình ống của HDAC8 với các dẫn xuất}

Molinspiration và SwissADMET đã được sử dụng để đánh giá các dẫn xuất giống thuốc dựa trên năm quy tắc của Lipinski (Lipinski et al., 1997) và quy tắc của Veber (Veber et al., 2002). Cả hai dẫn xuất đều hấp thu tốt và được xem là giống thuốc do không quy phạm cả năm quy tắc. Cụ thể, không nhiều hơn 5 nhóm cho liên kết hydro (số lượng các nhóm $-\mathrm{NH}$ và $-\mathrm{OH}), 7 \mathbf{7 h}$ có 3 nhóm và $7 \mathbf{v}$ có 4 nhóm. Không nhiều hơn 10 nhóm nhận hydro (bao gồm cả nguyên tử oxygen và nitrogen), khối lượng phân tử cả hai dẫn xuất đều nhỏ hơn 500 dalton, hệ số phân chia octanol-nước ( $\log \mathrm{P})$ của cả hai dẫn xuất đều không vượt quá 5 , số lượng liên kết có thể xoay được $\mathrm{n}$ rotb (number of rotatable bonds) của $7 \mathbf{h}$ và $7 \mathbf{v}$ đều dưới 10 ; độ khúc xạ mol $\mathrm{A}$ (molar refractivity) đều nằm trong giới hạn cho phép 40130 và giá trị TPSA (topological polar surface area) của các dẫn xuất đều nhỏ hơn 140. Kết quả được hiển thị trong Bảng 2.

Bảng 2. Kết quả dự đoán khả năng giống thuốc của hai dẫn xuất bằng Molinspiration và SwissADMET

\begin{tabular}{|c|c|c|c|c|c|c|c|}
\hline Dẫn xuất & $\begin{array}{r}\text { Khối lượng } \\
\text { phân tữ }\end{array}$ & $\log P^{2}$ & $\begin{array}{r}\text { Số nhóm cho liên } \\
\text { kết hydro }\end{array}$ & $\begin{array}{r}\text { Số nhóm nhận } \\
\text { hydro }\end{array}$ & $\mathbf{A}^{1}$ & TPSA $^{2}$ & $\overline{n \text { rotb }^{2}}$ \\
\hline $7 \mathrm{~h}$ & 348,38 & 2,25 & 3 & 7 & 88,68 & 104,73 & $\overline{6}$ \\
\hline $7 \mathrm{v}$ & 375,41 & 2,16 & 4 & 8 & 96,37 & 128,09 & 6 \\
\hline Belinostat & 318,35 & 2,19 & 3 & 6 & 82,18 & 95,50 & $\underline{2}$ \\
\hline
\end{tabular}

${ }^{1}$ Sủ dung SwissADMET

${ }^{2}$ Sủ dung Molinspiration

Bảng 3. Kết quả dụ̣ đoán khả năng hấp thụ của hai dẫn xuất bằng PreADMET

\begin{tabular}{crrrrrr}
\hline Dẫn xuất & HIA (\%) & $\begin{array}{l}\text { PCaco-2 } \\
(\mathbf{n m} / \mathbf{s})\end{array}$ & $\begin{array}{c}\text { Độ hòa tan trong nước } \\
\text { tinh khiết }(\mathbf{m g} / \mathbf{L})\end{array}$ & $\begin{array}{c}\text { Độ thẩm thấu } \\
\text { qua da }(\mathbf{c m} / \mathbf{g i o ̛ ̀})\end{array}$ & BBB & PPB (\%) \\
\hline $7 \mathrm{~h}$ & 90,033 & 0,712 & 70,243 & $-2,680$ & 0,177 & 88,850 \\
$7 \mathrm{v}$ & 84,356 & 0,383 & 6,779 & $-2,535$ & 0,103 & 92,401 \\
Belinostat & 89,937 & 0,474 & 103,593 & $-2,501$ & 0,182 & 94,264 \\
\hline
\end{tabular}

Bảng 3 cho thấy tất cả các hợp chất có giá trị hấp thụ qua đường ruột của con người HIA (human intestinal absorption) đều thuộc phạm vi các hợp chất hấp thu tốt (HIA: 70-100\%), dẫn xuất $7 \mathbf{h}$ cho kết quả tốt nhất 90,033\%. (Yazdanian et al., 1998). Kết quả dự đoán cho thấy cả hai dẫn xuất có độ hấp thu kém ở ruột thông qua mô hình tế bào Caco-2. Các tế bào Caco- 2 có nguồn gốc từ ung thư biểu mô tuyến ruột kết ở người và sở hữu nhiều con đường vận chuyển thuốc qua biểu mô ruột. Các chất được xem là có tính hấp thu tốt thường có giá trị $\mathrm{P}_{\mathrm{Caco-2}}$ lớn hơn $70 \mathrm{~nm} / \mathrm{s}$, độ hấp thu trung trình từ $4-70 \mathrm{~nm} / \mathrm{s}$. Dự đoán BBB (blood brain barrier) cho thấy các dẫn xuất hấp thụ trung bình và có khả năng đi xuyên qua hang rào máu não. Trong đó cả hai dẫn xuất đều cho kết quả thấp hơn belinostat, điều này rất quan trọng trong lĩnh vực dược phẩm vì các hợp chất có hoạt tính thần kinh trung ương phải đi qua nó và các hợp chất không có hoạt động thần kinh thì không được đi qua nó để tránh các tác dụng phụ liên quan đến thần kinh. Giá trị PPB (plasma protein binding) cho thấy mức độ liên kết với protein huyết tương của các dẫn xuất $\mathbf{7 v}$ tương đối tốt $92,401 \%$, ngược lại $\mathbf{7 h}$ 
được xem là liên kết yếu (nhỏ hơn 90\%), giá trị này một phần quyết định đến tác dụng của thuốc, vị trí và hiệu quả của thuốc. Thông số độ thấm của da được sử dụng trong ngành dược phẩm để đánh giá các sản phẩm hóa chất có nguy cơ trong trường hợp vô tình tiếp xúc với da. Các hợp chất được dự đoán có giá trị thẩm thấu qua da âm tính, kết quả khá an toàn.
Kết quả dự đoán độc tính bằng phần mềm Osiris Property Explorer (Bảng 4) và Toxtree (Bảng 5) cho thấy các dẫn xuất đều an toàn và tương đồng với chất đối chứng belinostat. Cụ thể, các dẫn xuất cho thấy độc tính rất thấp và an toàn, không gây kích ứng da và mắt, không gây đột biến, gây khối u hay là chất kích thích thần kinh, không ảnh hưởng đến quá trình sinh sản sau khi sử dụng.

Bảng 4. Kết quả dự đoán độc tính bằng màu sắc của hai dẫn xuất bằng Osiris Property Explorer

\begin{tabular}{cllll}
\hline Dẫn xuất & Gây đột biến & Gây khối u & Kích thích thần kinh & Ảnh hưởng đến sinh sản \\
\hline $7 \mathrm{~h}$ & Lam & Lam & Lam & Lam \\
$7 \mathrm{v}$ & Lam & Lam & Lam & Lam \\
Belinostat & Lam & Lam & Lam & Lam \\
\hline
\end{tabular}

Đỏ: độc tính cao nguy hiểm

Vàng: độc tính trung bình có thể sủ dụng

Lam: độc tính rất thấp hoạc không có độc tính, an toàn

Bảng 5. Kết quả dụ̣ đoán độc tính của hai dẫn xuất bằng Toxtree

\begin{tabular}{ccllll}
\hline Dẫn xuất & $\begin{array}{c}\text { Kích } \\
\text { ứng da }\end{array}$ & $\begin{array}{l}\text { Kích } \\
\text { úng mắt }\end{array}$ & $\begin{array}{l}\text { Âm tính với độc tố } \\
\text { duy truyền (đột } \\
\text { biến) gây ung thư }\end{array}$ & $\begin{array}{l}\text { Khả năng gây đột biến } \\
\text { S.Typhiurium TA100 } \\
\text { dựa trên QSAR }\end{array}$ & $\begin{array}{l}\text { Chất gây ung } \\
\text { thư tiềm ẩn dựa } \\
\text { trên QSAR }\end{array}$ \\
\hline $7 \mathrm{~h}$ & - & Không & Có & Không & Không \\
$7 \mathrm{v}$ & - & Không & Có & Không & Không \\
Belinostat & - & Không & Có & Không & Không \\
\hline
\end{tabular}

(-) Không xác định

Kết quả đánh giá khả năng gây ức chế trên kênh hERG (human ether-a-go-go related gene) của hai dẫn xuất bằng phần mềm preADMET (Bảng 6) cho kết quả dẫn xuất $\mathbf{7 v}$ tương đối tốt hơn belinostat và dẫn xuất $\mathbf{7 h}$ cho kết quả kém. Cụ thể, một số loại thuốc cho kết quả tốt về mặt lâm sàng trên thị trường

nhưng có xu hướng ức chế kênh hERG gây loạn nhịp tim, khả năng dẫn đến nhịp tim không đều gây tử vong (Haverkamp et al., 2000). Chính vì thế, việc xem xét về khả năng ức chế kênh $\mathrm{hERG}$ rất quan trọng cần phải tránh trong quá trình phát triển thuốc (Sanguinetti et al., 2006; Wang et al., 2012).

Bảng 6. Kết quả dự đoán độc tính của hai dẫn xuất bằng preADMET

\begin{tabular}{clll}
\hline \multirow{2}{*}{ Dẫn xuất } & $\begin{array}{l}\text { Khả năng gây đột biến } \\
\text { với chuột cống (Rat) }\end{array}$ & $\begin{array}{l}\text { Khả năng gây đột biến } \\
\text { với chuột nhà (Mouse) }\end{array}$ & Ú̉c chế kênh hERG ở người \\
\hline $7 \mathrm{~h}$ & Âm tính & Dương tính & Liều trung bình \\
$7 \mathrm{v}$ & Âm tính & Dương tính & Có khả năng \\
Belinostat & Âm tính & Dương tính & Liều thấp \\
\hline
\end{tabular}

Qua kết quả mô phỏng in silico cho thấy dẫn xuất $7 \mathbf{v}$ có tiềm năng về hoạt tính sinh học cao, mức độ độc đối với cơ thể thấp, vì vậy cần được đánh giá cụ thể hơn bằng các thử nghiệm sinh học in vitro và in vivo.

\section{KẾT LUẬN}

Một quy trình gồm 6 bước đã được thực hiện, đã tổng hợp thành công 2 dẫn xuất $7 \mathbf{h}$ và $7 \mathbf{v}$ có cấu trúc tương tự belinostat với hiệu suất toàn phần lần lượt là $3.51 \%$ và $2.63 \%$. Úng dụng thành công phản ứng Wittig vào quy trình để tổng hợp phần cầu nối trong cấu trúc của các dẫn xuất. Docking phân tử thành công các dẫn xuất đã tổng hợp vào enzyme HDAC8. Kết quả cho thấy các dẫn xuất có khả năng tương tác vào vùng hoạt động của $\mathrm{HDAC} 8$ và gây ức chế enzyme này. Thực hiện đánh giá khả năng giống thuốc và độc tính của hai dẫn xuất cho kết quả khá tương đồng với belinostat, các dẫn xuất được dự đoán không có độc tính với vật chủ khi sử dụng và có tiềm năng hoạt tính đầy hứa hẹn. Kết quả này được xem là cơ sở cho các nghiên cứu đánh giá in silico tiếp nối các bước phát triển, thiết kế thuốc sau này. Ngoài ra cần áp dụng các phương pháp thử nghiệm sinh học in vitro, in vivo để đánh giá đúng 
khả năng ức chế cũng như tiềm năng chống ung thư của hai dẫn xuất này.

\section{LÒ̀I CẢM ƠN}

Chúng tôi xin chân thành cảm ơn sự tài trợ quý báu của Trường Đại học Cần Thơ dành cho nghiên cứu này (Mã số: TSV2020-58).

\section{TÀI LIỆU THAM KHẢO}

Chakrabarti, A., Oehme, I., Witt, O., Oliveira, G., Sippl, W., Romier, C., \& Jung, M. (2015). HDAC8: a multifaceted target for therapeutic interventions. Trends in Pharmacological Sciences, 36(7), 481-492.

Chuang, D. M., Leng, Y., Marinova, Z., Kim, H. J., \& Chiu, C. T. (2009). Multiple roles of HDAC inhibition in neurodegenerative conditions. Trends in Neurosciences, 32(11), 591-601.

Dizon, D. S., Blessing, J. A., Penson, R. T., Drake, R. D., Walker, J. L., Johnston, C. M., \& Fader, A. N. (2012). A phase II evaluation of belinostat and carboplatin in the treatment of recurrent or persistent platinum-resistant ovarian, fallopian tube, or primary peritoneal carcinoma: a Gynecologic Oncology Group study. Gynecologic Oncology, 125(2), 367-371.

Dokmanovic, M., \& Marks, P. A. (2005). Prospects: histone deacetylase inhibitors. Journal of Cellular Biochemistry, 96(2), 293-304.

Giaccone, G., Rajan, A., Berman, A., Kelly, R. J., Szabo, E., Lopez-Chavez, A., \& Loehrer Sr, P. J. (2011). Phase II study of belinostat in patients with recurrent or refractory advanced thymic epithelial tumors. Journal of Clinical Oncology, 29(15), 2052.

Haverkamp, W., Breithardt, G., Cammm, A. J., Janse, M. J., Rosen, M. R., Antzelevitch, C., \& Shah, R. (2000). The potential for QT prorogation and proarrhythmia by nonantiarrhythmic drugs: clinical and regulatory implications. Eur Heart J. 21(15), 1216-1231.

Lipinski, C. A., Lombardo, F., Dominy, B. W., \& Feeney, P. J., 1997. Experimental and computational approaches to estimate solubility and permeability in drug discovery and development settings. Advanced Drug DeliveryRreviews. 23(1-3): 3-25.

Oehme, I., Deubzer, H. E., Wegener, D., Pickert, D., Linke, J. P., Hero, B., \& Witt, O. (2009). Histone deacetylase 8 in neuroblastoma tumorigenesis. Clinical Cancer Research, 15(1), 91-99.

Park, S. Y., Jun, J., Jeong, K. J., Heo, H. J., Sohn, J. S., Lee, H. Y., \& Kang, J. (2011). Histone deacetylases
1,6 and 8 are critical for invasion in breast cancer. Oncology Reports, 25(6), 1677-1681.

Ramalingam, S. S., Belani, C. P., Ruel, C., Frankel, P., Gitlitz, B., Koczywas, M., \& Gandara, D. (2009). Phase II study of belinostat (PXD101), a histone deacetylase inhibitor, for second line therapy of advanced malignant pleural mesothelioma. Journal of Thoracic Oncology, 4(1), 97-101.

Rodrigues, D. A., Ferreira-Silva, G. A., Ferreira, A. C., Fernandes, R. A., Kwee, J. K., Sant'Anna, C. M., \& Fraga, C. A. (2016). Design, synthesis, and pharmacological evaluation of novel $\mathrm{N}$ acylhydrazone derivatives as potent histone deacetylase 6/8 dual inhibitors. Journal of Medicinal Chemistry, 59(2), 655-670.

Ropero, S., \& Esteller, M. (2007). The role of histone deacetylases (HDACs) in human cancer. Molecular Oncology, 1(1), 19-25.

Sanguinetti, M. C., \& Tristani-Firouzi, M. (2006). hERG potassium channels and cardiac arrhythmia. Nature, 440(7083), 463-469.

Sawas, A., Radeski, D., \& O'Connor, O. A. (2015). Belinostat in patients with refractory or relapsed peripheral T-cell lymphoma: a perspective review. Therapeutic Advances in Hematology, 6(4), 202-208.

Veber, D. F., Johnson, S. R., Cheng, H. Y., Smith, B. R., Ward, K. W., \& Kopple, K. D. (2002). Molecular properties that influence the oral bioavailability of drug candidates. Journal of Medicinal Chemistry, 45(12), 2615-2623.

Verdin, E. (Ed). (2007). Histone deacetylases: transcriptional regulation and other cellular functions. Springer Science \& Business Media.

Wang, S., Li, Y., Wang, J., Chen, L., Zhang, L., Yu, H., \& Hou, T. (2012). ADMET evaluation in drug discovery. 12. Development of binary classification models for prediction of hERG potassium channel blockage. Molecular Pharmaceutics, 9(4), 996-1010.

Yazdanian, M., Glynn, S. L., Wright, J. L., \& Hawi, A. (1998). Correlating partitioning and Caco-2 cell permeability of structurally diverse small molecular weight compounds. Pharmaceutical Research, 15(9), 1490.

Yeo, W., Chung, H. C., Chan, S. L., Wang, L. Z., Lim, R., Picus, J., \& Goh, B. C. (2012). Epigenetic therapy using belinostat for patients with unresectable hepatocellular carcinoma: a multicenter phase I/II study with biomarker and pharmacokinetic analysis of tumors from patients in the Mayo Phase II Consortium and the Cancer Therapeutics Research Group. Journal of Clinical Oncology, 30(27), 3361. 